\title{
Stability limits and tuning recommendation of the classical current control providing inertia support
}

\author{
Sophie Coffey, Jennifer F. Morris, Agustí Egea-Àlvarez \\ PEDEC, Electronic and Electrical engineering department University of Strathclyde \\ Glasgow, UK \\ sophie.coffey@strath.ac.uk
}

\begin{abstract}
The drastic increase in renewable energy sources in power grids has raised stability concerns. A particular concern exists in the ability of the converters to preserve frequency stability, due to their inherent lack of inertia provision. Grid forming converters have been presented as a solution to this issue, however the control structure for such converters is significantly different from the vector current control structures utilized by most installed control-converter systems. The classical current controller with a Phase Locked Loop (PLL) can be modified to provide inertia by including an additional control loop that injects active power in the case of a frequency event. This paper presents a detailed stability study, using a small signal model, and presents a set of controller tuning recommendations for the classical current controller with inertia emulation capability. The investigation found that the classical current and PLL tuning decreases the power that can be provided using the inertia emulation loop. Reducing the current loop time constant can allow for stable inertia emulation with classical vector current control.
\end{abstract}

Index Terms-Inertia Emulation, Stability, Phase Locked Loop (PLL), Short Circuit Ratio (SCR)

\section{INTRODUCTION}

With manmade climate change causing natural disasters, rising sea levels, ecological loss, and an increase in inequality, the UN IPCC 2018 report outlined significant action that must be taken to reduce future global warming to under $1.5^{\circ} \mathrm{C}$ [1]. This has resulted in conventional fossil fuel power stations, with synchronous generators, being replaced with renewable energy sources (RES). In 2020, the European installed renewable capacity was rated at 573,266 MW [2]. RES are usually interfaced by power electronic devices compared to the synchronous machines used in standard power stations. The rotating masses of the synchronous generators provide inertia to be released into the grid during frequency or angle disturbances [3]. However, generation connected to the grid through power converters, lack this inherent inertia because the rotating parts of the renewable source are decoupled from the grid when utilizing classical current control [4]. The lack of inertia threatens the stability of the power network, as with a low inertia system the rate of change of frequency (RoCoF) is much higher and the system can be more easily destabilized
[5] [6]. Because of this, small and medium power networks, such as those in Ireland, Texas, and the UK, are facing increasing challenges [7]. Renewable sources also produce an issue with intermittent generation; for this reason, large energy storage systems have been proposed [8].

The classical current controller used in the major part of gridconnected applications is defined as grid following converter, which relies on a strong grid to operate. Grid following converters use a phase locked loop (PLL) to measure the grid electrical angle from the point of common coupling (PCC) and cannot provide inertia in its basic implementation.

One solution presented to provide inertia using power converters, are Virtual Synchronous Machines (VSMs), a particular type of grid forming converter. They provide inertia by emulating the behaviour of conventional synchronous machines during a frequency disturbance [9]. However, the VSM control structure, with the grid forming capabilities it provides, is significantly different to the traditional current controller, which is currently widespread and utilized by most manufacturers [10]. Another solution is to add an additional loop to the classical current control to provide inertia emulation without modifying the present control structure [6]. The benefit of using this model would be that the control structure would not need to be changed much and existing installed control mechanisms can be used. Furthermore, the conventional current controller has a faster transient response than that of a typical VSM which is a greatly desirable feature [11], [12], [13]. [14] reviewed the performance of grid following converters with inertia emulation, grid forming converters and VSMs and concluded that from the frequency point of view, all provided the same behaviour. Therefore, the grid following converter should not be discounted as a viable option as converter penetration continues to rise.

This paper investigates the limitations and optimal tuning of the PLL and current loop for a current controller with an inertia emulation branch, for varying grid strengths. The introduction of this branch has been found to affect system stability and only a limited inertial gain could be introduced. Therefore, the authors investigated methods to allow for a higher inertial gain whilst maintaining system stability. The current loop and PLL gain values are often restricted to a set range, so a series of 
parametric sweeps were run to investigate the effect of these parameters on achieving an increased inertial gain. Recommendations for PLL and current loop tuning to maximise the power provided by the inertia loop are given.

\section{SYSTEM UNDER STUDY}

The system investigated is a $3 \mathrm{MW}, 690 \mathrm{~V}$ grid connected twolevel VSC converter, similar to a wind turbine or energy storage system (figure 1). The converter is connected to the grid through an RL filter and a shunt capacitor $C_{f}$ for filtering the PWM harmonics. In this study a constant DC link has been assumed. The grid is modelled as the Thevenin equivalent [14] and will be studied for varying short circuit ratio (SCR) values (2-5). The grid is modelled in the $d q$ synchronous reference frame, represented in the state space form:

$$
\begin{gathered}
\dot{\mathrm{x}}=\mathrm{A}_{\mathrm{lc}} \mathrm{x}+\mathrm{B}_{\mathrm{lc}} \mathrm{u} \\
\mathrm{y}=\mathrm{C}_{\mathrm{lc}} \mathrm{x}
\end{gathered}
$$

Where $C_{l c}$ is a 3 by 3 identity matrix and $A_{l c}, B_{l c}$, and are the state matrices, defined by:

$$
\begin{aligned}
& \mathrm{A}_{\mathrm{lc}}=\left[\begin{array}{cccccc}
-\mathrm{R}_{\mathrm{c}} / \mathrm{L}_{\mathrm{c}} & -\omega_{\mathrm{n}} & 1 / \mathrm{L}_{\mathrm{c}} & 0 & 0 & 0 \\
\omega_{\mathrm{n}} & -\mathrm{R}_{\mathrm{c}} / \mathrm{L}_{\mathrm{c}} & 0 & 1 / \mathrm{L}_{\mathrm{c}} & 0 & 0 \\
-1 / \mathrm{C}_{\mathrm{f}} & 0 & 0 & -\omega_{\mathrm{n}} & 1 / \mathrm{C}_{\mathrm{f}} & 0 \\
0 & -1 / \mathrm{C}_{\mathrm{f}} & \omega_{\mathrm{n}} & 0 & 0 & 1 / \mathrm{C}_{\mathrm{f}} \\
0 & 0 & -1 / \mathrm{L}_{\mathrm{n}} & 0 & -\mathrm{R}_{\mathrm{n}} / \mathrm{L}_{\mathrm{n}} & 0 \\
0 & 0 & 0 & -1 / \mathrm{L}_{\mathrm{n}} & \omega_{\mathrm{n}} & -\mathrm{R}_{\mathrm{n}} / \mathrm{L}_{\mathrm{n}}
\end{array}\right] \\
& \mathrm{B}_{\mathrm{lc}}=\left[\begin{array}{cccc}
-1 / \mathrm{L}_{\mathrm{c}} & 0 & 0 & 0 \\
0 & -1 / \mathrm{L}_{\mathrm{c}} & 0 & 0 \\
0 & 0 & 0 & 0 \\
0 & 0 & 0 & 0 \\
0 & 0 & 1 / \mathrm{L}_{\mathrm{n}} & 0 \\
0 & 0 & 0 & 1 / \mathrm{L}_{\mathrm{n}}
\end{array}\right]
\end{aligned}
$$

where $L_{n}$ and $R_{n}$ are the grid Thevenin equivalent inductance and resistance, $\omega_{n}$ is the grid frequency, $L_{c}$ and $R_{c}$ are the converter inductance and resistance, and $C_{f}$ is the filter capacitance. For this grid system, the states, inputs and outputs are defined by $x_{l c}, u_{l c}$ and $y_{l c}$ :

$$
\begin{gathered}
\mathrm{x}_{\mathrm{lc}}=\left[\mathrm{i}_{\mathrm{cd}}, \mathrm{i}_{\mathrm{cq}}, \mathrm{u}_{\mathrm{d}}, \mathrm{u}_{\mathrm{q}}, \mathrm{i}_{\mathrm{nd}}, \mathrm{i}_{\mathrm{nq}}\right] \\
\mathrm{u}_{\mathrm{lc}}=\left[\mathrm{v}_{\mathrm{d}}, \mathrm{v}_{\mathrm{q}}, \mathrm{e}_{\mathrm{d}}, \mathrm{e}_{\mathrm{q}}\right] \\
\mathrm{y}_{\mathrm{lc}}=\left[\mathrm{i}_{\mathrm{ld}}, \mathrm{i}_{\mathrm{lq}}, \mathrm{u}_{\mathrm{d}}, \mathrm{u}_{\mathrm{q}}\right]
\end{gathered}
$$

Where $i_{c q d}$ is the current through the coupling filter, $i_{\text {nqd }}$ is the current through the grid equivalent, $e_{q d}$ is the grid voltage, $v_{q d}$ is the converter voltage, and $\mathrm{u}_{\mathrm{qd}}$ is the voltage from the PCC.

\section{A. Overall Control Structure}

The converter control is based on classic current control and is depicted in figure 1, [14]. The current controller consists of two PI controllers, two decoupling terms and a voltage feedforward. The PI controller for the current loop, $\mathrm{K}_{\mathrm{CC}}(\mathrm{s})$, is tuned as in [14]:

$$
\begin{aligned}
\mathrm{K}_{\mathrm{cc}}(\mathrm{s}) & =\left(\mathrm{Kp}_{\mathrm{cc}} \mathrm{s}+\mathrm{Ki}_{\mathrm{cc}}\right) / \mathrm{s} \\
\mathrm{Kp}_{\mathrm{cc}} & =\mathrm{L}_{\mathrm{c}} / \tau_{\alpha} \\
\mathrm{Ki}_{\mathrm{cc}} & =\mathrm{R}_{\mathrm{c}} / \tau_{\alpha}
\end{aligned}
$$

Where $\tau_{\alpha}$ is the current loop time constant, and is recommended to be 5 to 10 times slower than the switching frequency [14], which is in the range $1-2 \mathrm{kHz}$ [15], up to 10 $\mathrm{kHz}$ [17]. Therefore, for the classical current controller, the optimal time constant has been considered to be 1-5 ms.

The PLL gain, $K_{P L L}(s)$ is defined as:

$$
\mathrm{K}_{\mathrm{PLL}}(\mathrm{s})=\frac{\mathrm{Kp} \text { PLL } \mathrm{S}+\mathrm{Ki} \mathrm{i}_{\mathrm{PL}}}{\mathrm{s}}
$$

With gain values calculated using:

$$
\begin{aligned}
K p_{P L L} & =\frac{2 \omega_{n} \zeta}{E_{m}} \\
K i_{P L L} & =\frac{K p_{P L L}}{\tau_{P L L}}
\end{aligned}
$$

Where $E_{m}$ is the admitted voltage, $\zeta$ is the damping ratio, and $\tau_{P L L}$ is the PLL bandwidth. The optimal $\tau_{P L L}$ has traditionally been tuned using [17]:

$$
\tau_{\mathrm{PLL}}=\frac{2 \zeta}{\omega_{n}}
$$

Which is used in turn, to tune the proportional and integral PLL gains. Initially, the current loop was tuned with a current loop time constant of $2 \mathrm{~ms}$, and the PLL time constant to $4.5 \mathrm{~ms}$.

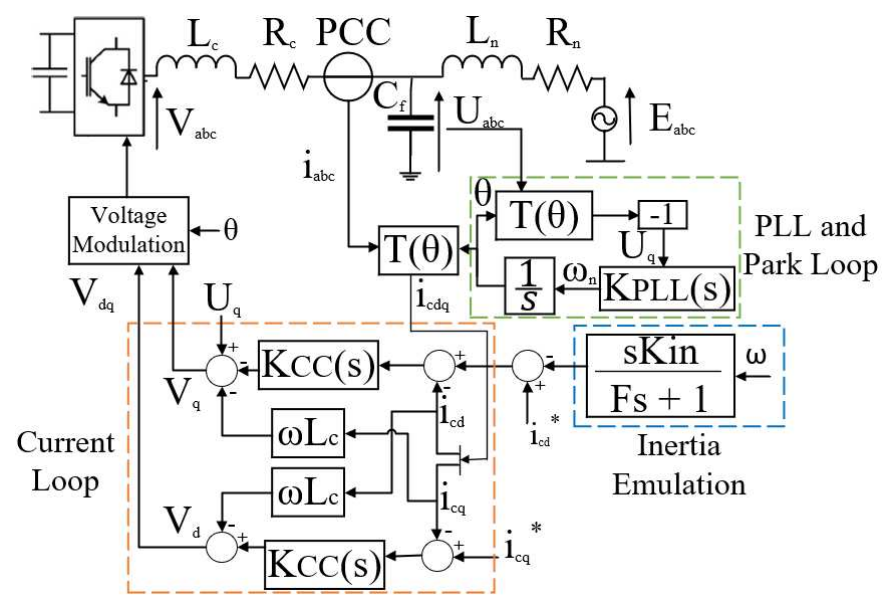

Figure 1. Electrical scheme of studied Converter and control

\section{B. Inertia Emulation}

Inertia is emulated with the inertia branch, the output of which is added to the reference $i_{d}{ }^{*}$ current to form the total reference current [6]. A gain, $K_{i n}$ amplifies the rate of change of frequency. As the PLL provides the frequency of the grid, a derivative term and a low pass filter are added to improve the system stability:

$$
\mathrm{i}_{\text {dfreq }}=\frac{\mathrm{sK}_{\text {in }}}{\mathrm{Fs}+1}
$$

Where $F$ is the first order filter time constant.

The inertia gain $K_{\text {in }}$ also determines the required power to be delivered to the grid during a frequency disturbance [18]. The gain of the inertia controller can be obtained from the synchronous generator swing equation and therefore the maximum power delivery required for a particular RoCoF [7], which can be simplified to:

$$
\mathrm{P}_{\text {emulation max }}=\frac{2 \mathrm{HS}_{\mathrm{base}}}{\omega_{\mathrm{n}}} \Delta \omega_{\max }
$$


Where $S_{\text {base }}$ is the rated power of the turbine, $H$ is the inertia constant emulated (seconds), $\omega_{s}$ is the synchronous frequency and $\dot{\omega}_{\text {max }}$ is the maximum allowable RoCoF $(\mathrm{Hz} / \mathrm{s})$.

The required power should be divided by the nominal voltage and RoCoF to obtain the gain $K_{i n}$. The inertial branch gain is therefore:

$$
\mathrm{K}_{\text {in }}=\frac{\mathrm{P}_{\text {emulation max }}}{\mathrm{V}_{\text {nom }} \Delta \omega_{\max }}=\frac{2 \mathrm{HS}_{\text {base }}}{\omega_{\mathrm{s}} \mathrm{V}_{\text {nom }} \sqrt{ }(3 / 2)}
$$

A typical required inertia constant, $H$, for a $3 \mathrm{MW}$ system ranges from approximately 1-5 s [19] [21].

\section{SMALL SIGNAL MODEL}

The converter-controller system was linearised, and a smallsignal model created to observe the effect of a small disturbance on the stability of the system. The general representation of a small-signal model is:

$$
\begin{gathered}
\Delta \dot{\mathrm{x}}=\mathrm{A} \Delta \mathrm{x}+\mathrm{B} \Delta \mathrm{u} \\
\Delta \mathrm{y}=\mathrm{C} \Delta \mathrm{x}+\mathrm{D} \Delta \mathrm{u}
\end{gathered}
$$

Figure 2 shows the linearised system and the connections of the different components. The current loop [14] and the electrical system, given in (3), are already linear models. The linearised models of the PLL and Park transformation and Park inverse transformation used in this paper are derived in [14].

$$
\begin{aligned}
& \stackrel{\Delta \omega}{\longrightarrow} \underset{\text { Gain }}{\text { Inertial }} \mathrm{i}_{\text {freq }}{ }^{*} \mathrm{i}_{\mathrm{q}}{ }^{*} \mathrm{i}_{\mathrm{d}}{ }^{*}
\end{aligned}
$$

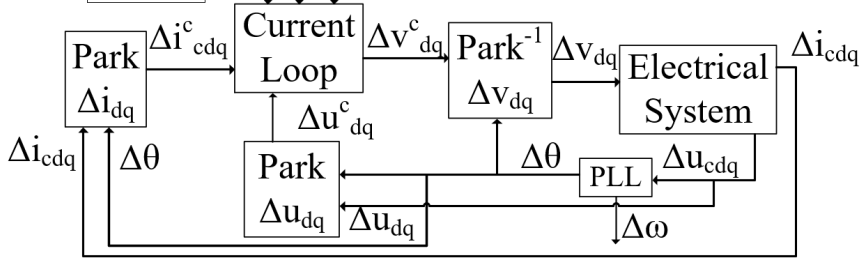

Figure 2. Small Signal Representation

The inertia response of this small-signal system was implemented by the transfer function previously shown in (14). A time domain model was designed and simulated in Matlab, with Simulink, to validate the results of the small-signal model, with SCR values ranging from 2 to 5 . The time domain and small signal model (SSM) responses to a power step are shown in figure 3. As it can be seen, both models overlay, validating the small signal model.

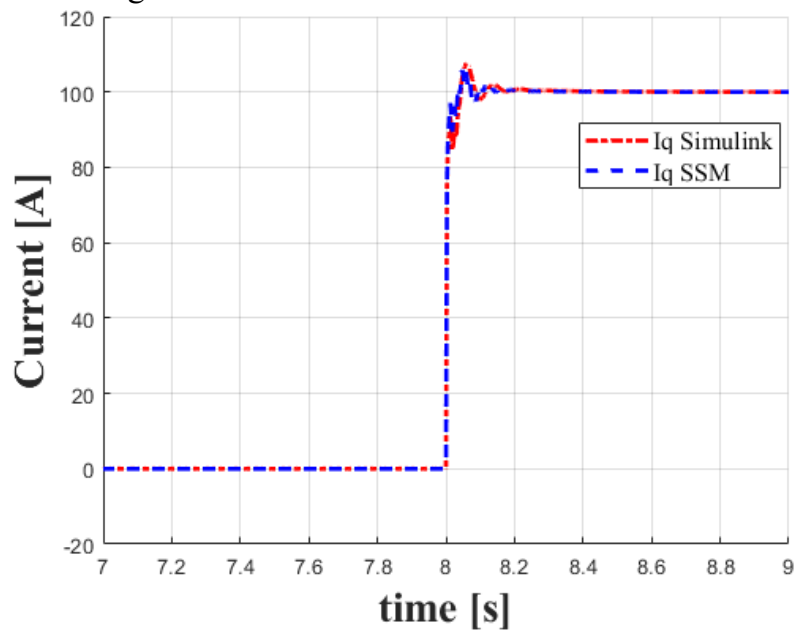

Figure 3. Time domain and SSM response

\section{A. Investigation}

The SSM was used to perform a parametric sweep for increasing values of $K_{\text {in }}$ and $F$ in order to identify the impact of each parameter on stability. This produced the stability limits of the system under varying conditions and isolated the optimum PLL and current loop tunings. The eigenvalues of the SSM were analysed to determine system stability; any poles in the right-hand plane indicated system instability. The specific investigations carried out to achieve this are as follows:

- Determining the maximum $\mathrm{K}_{\text {in }}$ gain whilst maintaining stability with increasing $\mathrm{F}$ filter constant for changing SCR.

- Investigate the effect of changing PLL time constant, $\tau_{P L L}$, on stability considering the inertia loop.

- Investigate the impact of the current controller time constant, $\tau_{\alpha}$, and its effect on system considering the inertia loop.

\section{RESUlTS}

\section{A. Impact of $K_{\text {in }}$ and $F$ with varying $S C R$}

The first investigation was to observe the maximum value of $K_{\text {in }}$ and $F$ which had a stable condition when classic PLL and current control tuning were considered for different SCR values from 2 to 5 . The initial tuning of the converter has been obtained from well-established tuning rules and resulted in a current loop time constant, $\tau_{\alpha}$ of $2 \mathrm{~ms}$, and a PLL time constant, $\tau_{P L L}$, of $0.0045 \mathrm{~s}$ [17].

Figure 4 shows the stability limit for different SCR and $F$ values, and a linear relationship between the maximum value of $K_{\text {in }}$ and $F$ is observed. Also, it can be seen that as the SCR is decreased, the maximum inertial gain for a stable system at a given filter constant reduces.

The line of stability continues as both $K_{\text {in }}$ and $F$ increase, however, there reaches a point where the filter value is too great and degrades the dynamic response of the power injection during a frequency disturbance.

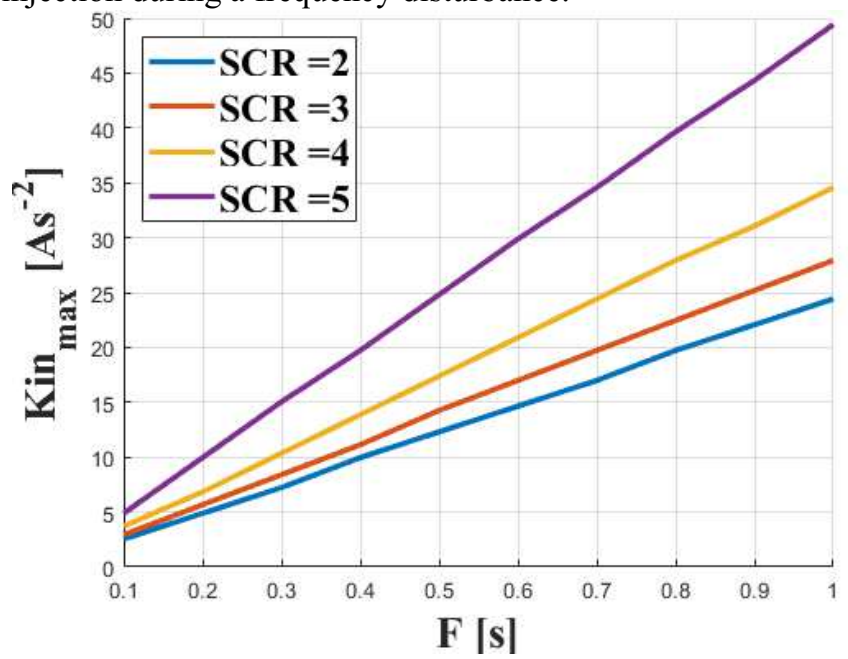

Figure 4. $\mathrm{K}_{\text {inmax }}$ against $\mathrm{F}$ Stability limit for varying $\mathrm{SCR}, \tau_{P L L}=0.0045 \mathrm{~s}, \tau_{\alpha}$ $=0.002 \mathrm{~s}$

The limiting effect of the filter constant can be observed in figure 5 which shows that for a constant value of $K_{\text {in }}\left(12 \mathrm{As}^{-2}\right)$, the value of $F$ significantly affects the performance. An $F$ of 
$0.3 \mathrm{~s}$ produces an acceptable dynamic performance, however, when $F$ is increased to $0.9 \mathrm{~s}$, the dynamic performance is much slower. Equation (15) is used to calculate the power required to be transferred by the converter. If a value of $24 \mathrm{~kW}$ is required, figure 5 shows that this is not achieved by the system with $F 0.9$ s. Therefore, it is recommended that $F$ is tuned to be fast enough for an appropriate dynamic response but slow enough to filter out standard frequency deviations that the system is not required to respond to.

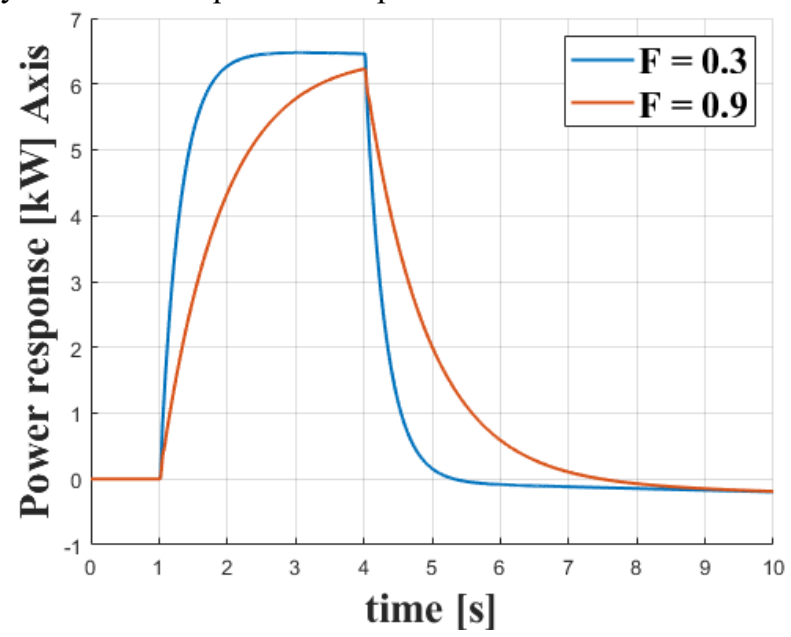

Figure 5. Power [kW] Response to $1 \mathrm{p} . \mathrm{u}$ ramp increase in frequency: $\mathrm{K}_{\mathrm{in}}=$ $8, \mathrm{~F}=0.3 \mathrm{~s}, \mathrm{~F}=0.9 \mathrm{~s}$

\section{B. $K_{\text {in }}$ against $\tau_{P L L}$}

The effect of increasing $\tau_{P L L}$ on the stability of the system was studied for varying $F$ values. Figure 6 shows the maximum $K_{\text {in }}$ that can be employed as $\tau_{P L L}$ is increased, with $\tau_{\alpha}$ kept constant at $2 \mathrm{~ms}$. For all values of $F$, the maximum $K_{\text {in }}$ gain that can be achieved increased with an increasing $\tau_{P L L}$ and then plateaus. The plateau begins at $0.04 \mathrm{~s}$ for $F=0.1 \mathrm{~s}, \tau_{P L L}=0.15 \mathrm{~s}$ for $F=$ $0.5 \mathrm{~s}$.

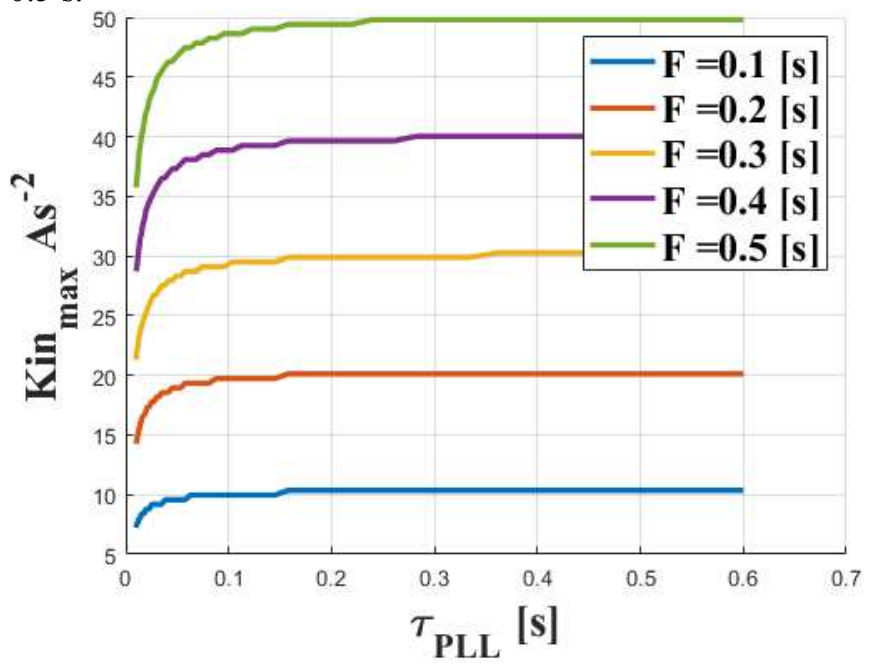

Figure 6. SCR $5 \mathrm{~K}_{\text {inmax }}$ against $\tau_{\mathrm{PLL}}$

As expected, increasing the filter time constant increased the maximum $K_{\text {in }}$ gain that could be achieved for a stable system. As the PLL time constant is increased, the stability limit increases at first, but then reaches a plateau. Based on the location of this plateau, a new $\tau_{P L L}$ constant of $0.04 \mathrm{~s}$ was selected, 10 times slower than the previously defined optimal tuning. Figure 6 demonstrate that increasing the time constant past this value would have no further impact on stability.

It was therefore concluded that the optimal PLL time constant to be selected for this system was $0.04 \mathrm{~s}$.

\section{C. $K_{\text {in }}$ against $\tau_{\alpha}$ Current Controller time constant}

The maximum value of $K_{\text {in }}$ that can be achieved as the current controller time constant is varied was simulated at multiple values of $F$. Note that (8) and (9) are considered to give optimal tunings for vector current control, which results in a current control time constant in the range $\tau_{\alpha}=2-5 \mathrm{~ms}$ [14]. The optimal PLL bandwidth is given by (13).

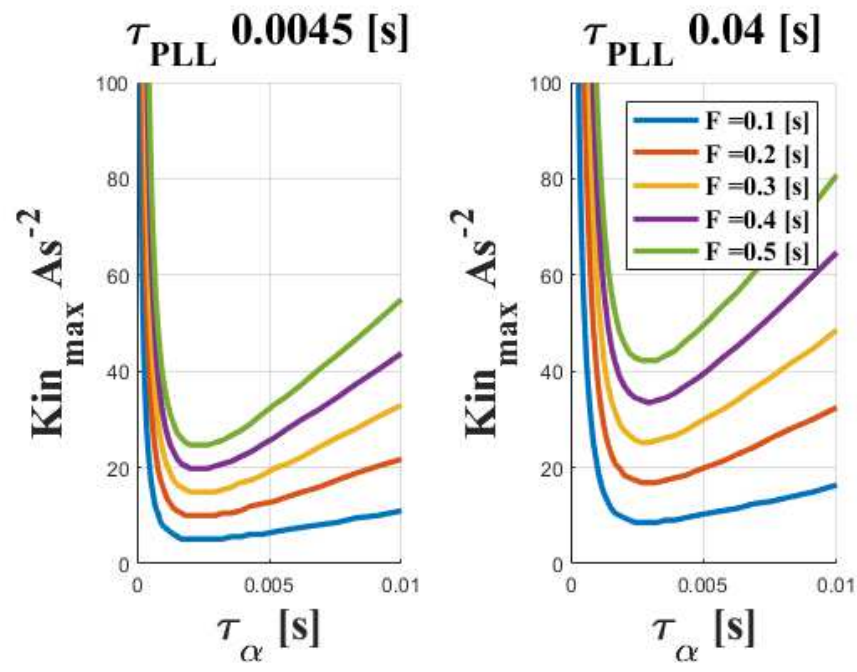

Figure 7. $\mathrm{K}_{\text {inmax }}$ vs $\left.\left.\tau_{\alpha} \mathrm{SCR} 5 \mathrm{a}\right) \tau_{\mathrm{PLL}}=2 \mathrm{e} / \mathrm{wn}=0.0045 \mathrm{~s} \mathrm{~b}\right) \tau_{\mathrm{PLL}}=0.04 \mathrm{~s}$

Figure 7 a shows the effect on the maximum value of $K_{\text {in }}$ of increasing $\tau_{\alpha}$ with $\tau_{P L L}$ fixed at the assumed optimum value of $0.0045 \mathrm{~s}$, and in a grid with $\mathrm{SCR}=5$. Figure $7 \mathrm{~b}$ shows the same system simulation but with $\tau_{P L L}$ fixed at the new optimum value, found in the previous section, i.e. $\tau_{P L L}=0.04 \mathrm{~s}$. A significant increase in the maximum $K_{\text {in }}$ that maintains stability can be seen with the new value of $\tau_{P L L}$. Figure 7 also shows that, for a set value of $K_{i n}$, the controller is most stable with either a very fast $\tau_{\alpha}$ or a slow value. There is a dip in stability at $1.5-10 \mathrm{~ms}$, above which the system stability begins to rise again allowing for increased $\mathrm{K}_{\mathrm{in}}$. The stability recovers with a $\tau_{\alpha}$ of $0.1 \mathrm{~s}$ or greater for SCR 5, and F of $0.5 \mathrm{~s}$. However, with SCR 5 and F of $0.1 \mathrm{~s}$, the system requires a much larger time constant for stability with an increased $K_{i n}$.

The system can achieve high inertial gains for current loop time constants less than $1 \mathrm{~ms}$, but then begins to deteriorate, dipping to a minimum at around $2 \mathrm{~ms}$. The system then recovers, and the gain begins to increase again, but the time constant has to be to about $0.1 \mathrm{~s}$ to achieve a high $K_{i n}$. 


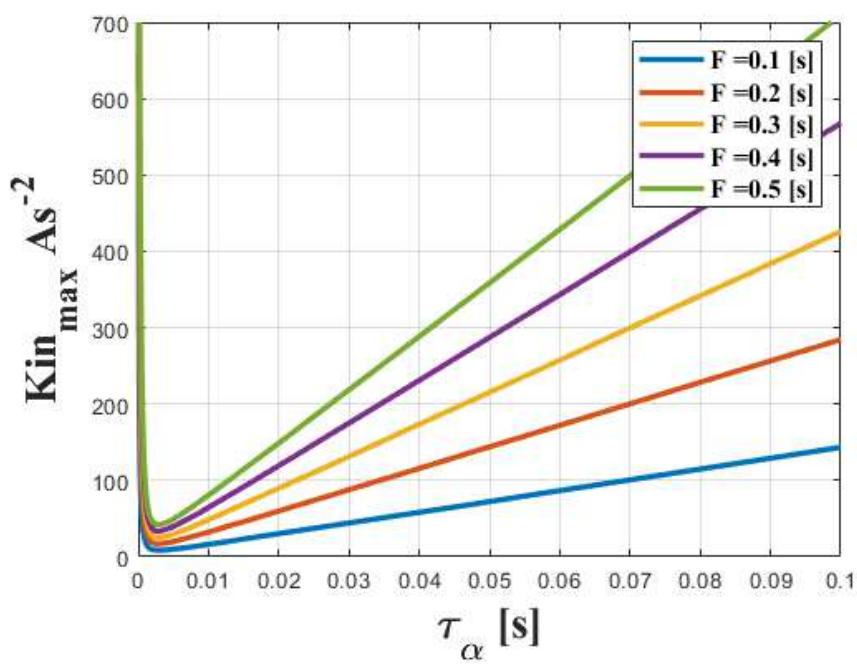

Figure 8. SCR 5 Increased $\tau_{\alpha}$ range

The analysis was repeated at $\mathrm{SCR}=4,3$ and 2, as shown in figure 9. As the SCR decreases, the dip in stability begins at a slightly lower $\tau_{\alpha}$. Furthermore, for the same $F$, reducing the SCR reduces the maximum $K_{i n}$ at the given $\tau_{\alpha \text {. }}$
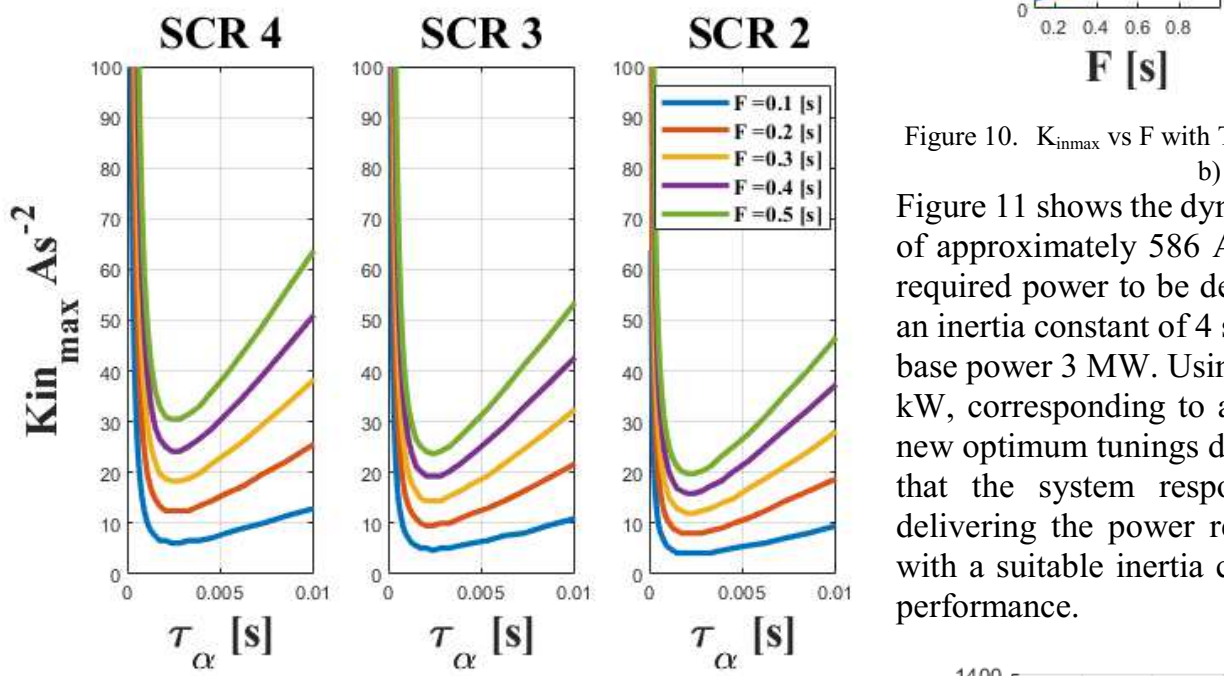

Figure 9. $\mathrm{K}_{\text {inmax }}$ against $\tau_{\alpha}$ a) SCR 4, b) SCR 3, c) SCR 2

This analysis shows that the classical choice of a current loop time constant in the range 1-5 ms gives the lowest possible maximum inertial gain. Therefore, a much faster or much lower time constant is recommended, which is discussed in the following section.

\section{RECOMMENDATIONS AND THEIR LIMITATIONS}

\section{A. Inertia emulation capability in fast operation}

From this investigation, it was determined that for the set system parameters, the ideal system tuning can be determined from running parametric sweeps of $K_{\text {inmax }}$ against $\tau_{P L L}$ and against $\tau_{\alpha}$. A PLL time constant of $0.04 \mathrm{~s}$ was recommended. However, the optimal regions for current controller time constant would be $0.1 \mathrm{~ms}$, or a value of $0.1 \mathrm{~s}$ or more. This would allow the $K_{\text {in }}$ gain to be increased to achieve the required power transfer required to emulate inertia.
Figure 10 shows the response of the system with $\tau_{\alpha}=0.1 \mathrm{~ms}$, $10 \mathrm{~ms}$, and $100 \mathrm{~ms}$. The $0.1 \mathrm{~ms}$ and $100 \mathrm{~ms}$ systems allow high inertial gains, but with $\tau_{\alpha}=10 \mathrm{~ms}$ the system cannot reach gains higher than $100 \mathrm{As}^{-2}$. The implication of this means the maximum inertial power is reduced. The SCR 5 provides the highest possible inertial gain, but any SCR lower than this has a significant drop in maximum possible $K_{i n}$.

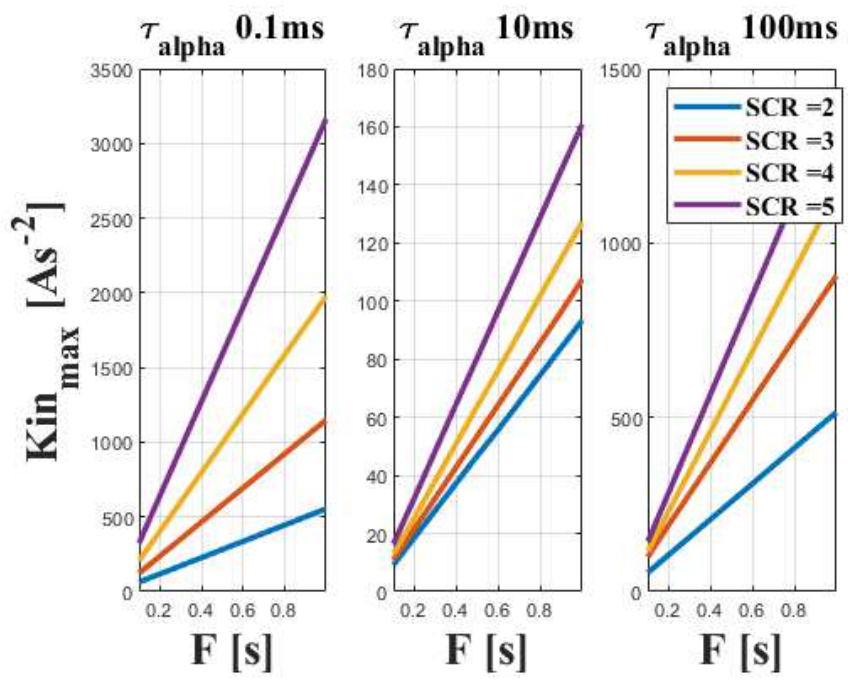

Figure $10 . K_{\text {inmax }}$ Vs F with Tuning Recommendations $\tau_{\text {PLL }} 0.4 \mathrm{~s}$, a) $\tau_{\alpha} 0.1 \mathrm{~ms}$ b) $\left.\tau_{\alpha} 10 \mathrm{~ms} \mathrm{c}\right) \tau_{\alpha} 100 \mathrm{~ms}$

Figure 11 shows the dynamic response of the system with a $K_{\text {in }}$ of approximately $586 \mathrm{As}^{-2}$ and a filter constant of $0.5 \mathrm{~s}$. The required power to be delivered was calculated from requiring an inertia constant of $4 \mathrm{~s}$, a RoCoF of $2.5 \mathrm{~Hz} / \mathrm{s}$, and the system base power $3 \mathrm{MW}$. Using (15), the power calculated was 1200 $\mathrm{kW}$, corresponding to an inertial gain of $568 \mathrm{As}^{2}$. Using the new optimum tunings developed in this section, it can be seen that the system responds effectively and is capable of delivering the power required by the frequency disturbance with a suitable inertia constant, $\mathrm{H}$, with appropriate dynamic performance.

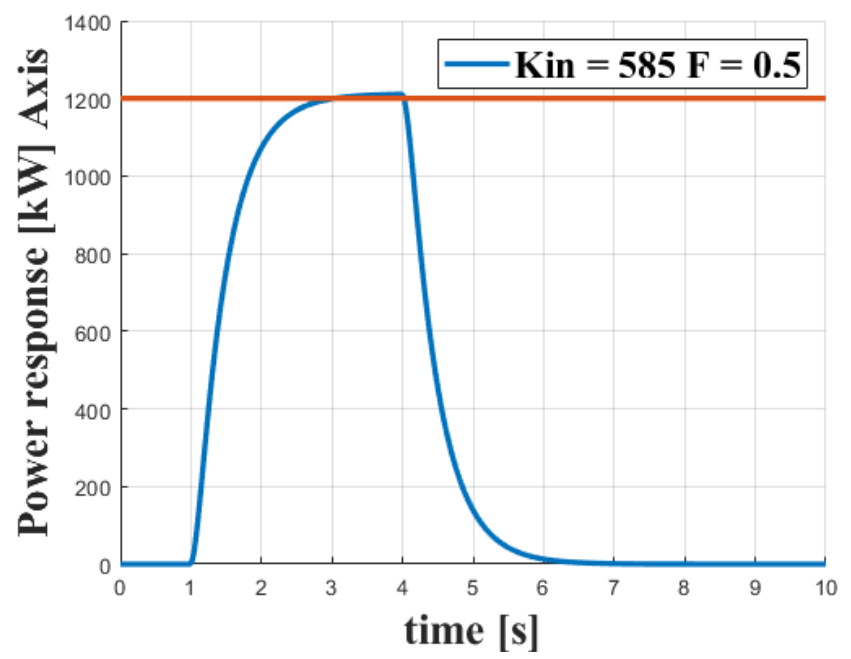

Figure 11. Power Response for system: $\tau_{\alpha}=0.1 \mathrm{~ms}, \tau_{\mathrm{PLL}}=0.04 \mathrm{~s}, \mathrm{SCR} 5, \mathrm{~K}_{\mathrm{in}}$ $=585 \mathrm{As}^{-2}, \mathrm{~F}=0.5$ 


\section{B. Classical current controller operation region}

Current controller time constants are limited by the switching time of the converter; they should be 5 to 10 times slower than the converter switching frequency [14]. The average switching frequency for a $3 \mathrm{MW}$ wind turbine to grid converter connection is about $1-2 \mathrm{kHz}$, up to about $10 \mathrm{kHz}$ [17]. Therefore, the fastest response of the current controller is about $1 \mathrm{~ms}, 10$ times slower than the recommended value. The classical current controller value is around $2-5 \mathrm{~ms}$, which the graphs in figure 7 to figure 9 show is the least stable region of operation. Therefore, it is recommended, that for current controller inertial emulation, the current controller time constants must be reduced to increase stability during frequency disturbances to obtain a high inertial gain that can deliver or absorb power during the disturbance. The classical current controller time constant region of operation is very limited for this type of inertia emulation.

\section{CONCLUSION}

In this study, inertia capabilities were replicated successfully in the traditional current controller by adding an inertial gain, amplifying the rate of change of frequency of the system, and a filter. A series of parametric sweeps were performed for varying filter constants and current controller and PLL time constants. This investigation highlighted that in the normal area of tuning, $\tau_{\alpha}$ of $1-5 \mathrm{~ms}$, the inertia emulation performs poorly, i.e. it is unable to reach the gains required for emulating inertia. If $\tau_{\alpha}$ is reduced to fast values of around $0.1 \mathrm{~ms}$, then stable inertia emulation with classical vector current control can be achieved.

\section{REFERENCES}

[1] V. Masson-Delmotte, P. Zhai, H.-O. Pötner, D. Roberts, J. Skea, P. R. Shukla and e. al., "IPCC, 2018: Global Warming of $1.5^{\circ} \mathrm{C}$. An IPCC Special Report on the impacts of global warming of $1.5^{\circ} \mathrm{C}$ above preindustrial levels and related global greenhouse gas emission pathways...," ISBN, 2018.

[2] IRENA, "Renewable capacity statistics 2020 International Renewable Energy Agency (IRENA)," ISBN, Abu Dhabi, 2020.

[3] C. Mosca, F. Arrigo, A. Mazza, E. Bompard, E. Carpaneto, G. Chicco and P. Cuccia, "Mitigation of Frequency Stability Issues in Low Inertia Power Systems using Synchronous Compensators and Battery Energy Storage Systems," IET Generation, Transmission \& Distribution, vol. 13, no. 17, pp. 3951-3959, 2019.

[4] T. Ackermann, T. Prevost, V. Vittal, A. J. Roscoe, J. Matevosyan and N. Miller, "Paving the Way: A Future Without Inertia is Closer Than You Think," IEEE Power and Energy Magazine, vol. 15, no. 6, pp. 61-69, 2017.

[5] F. Milano, F. Dorfler, G. Hug, D. J. Hill and V. Gregor, "Foundations and challenges of low-inertia systems," in 2018 Power Systems Computation Conference (PSCC), Dublin, 2018.

[6] J. Morren, S. W. H. d. Haan, W. L. Kilng and J. A. Ferreira, "Wind turbines emulating inertia and supporting primary frequency control," IEEE Transactions on Power Systems, vol. 21, no. 1, pp. 433-434, 2006.

[7] B. Hartmann, I. Vokony and I. Táczi, "Effects of decreasing synchronous inertia on power system dynamics - Overview of recent experiences and marketisation of services," International Transactions on Electrical Energy Systems, vol. 29, no. 12, 12 June 2019.

[8] G. A. Ramos, M. A. Rios, F. D. Gómez, H. Palacios and L. A. Posada, "Power quality study of large-scale wind farm with battery energy storage system," in IEEE Industry Applications Society Annual Meeting, Cincinnati, 2017.

[9] H. Bevrani, T. Ise and Y. Muira, "Virtual synchronous generators: a survey and new perspectives," Electrical Power and Energy Systems, vol. 54, pp. 244-254, 2013.

[10] A. Abdelrahim, M. Smailes, K. Ahmed, A. Egea-Àlvarez and P. McKeever, "Modified grid forming converter controller with fault ride through capability without PLL or current loop," in 18th Wind Integration Workshop, Dublin, 2019.

[11] IEEE, "Practical power flow controller brings benefits of power electronics to the grid," 18 May 2018. [Online]. Available: https://events.vtools.ieee.org/m/169041. [Accessed 12 October 2020].

[12] J.-W. Choi and S.-K. Sul, "Fast current controller in three-phase $\mathrm{AC} / \mathrm{DC}$ boost converter using $\mathrm{d}-\mathrm{q}$ axis crosscoupling," IEEE Transactions on Power Electronics, vol. 13, no. 1, pp. 179-185, 1998.

[13] A. Tayyebi, F. Dörfler, F. Kupzog, Z. Miletic and W. Hribernik, "Grid-forming converters - inevitability, control strategis and challenges in future grid application," in Cired Workshop, Ljubljana, 2018.

[14] F. D'Agostino, S. Massuco, G.-P. Schiapparelli, F. Silvestro and M. Paolone, "Performance Comparative Assessment of Grid Connected Power Converters Control Strategies," in 2nd IEEE International Conference on Industrial Electronics for Sustainable Energy Systems (IESES), Cagliari, 2020

[15] A. Egea-Alvarez, S. Fekriasl, F. Hassan and O. Gomis-Bellmunt "Advanced vector control for voltage source converters connected to weak grids," IEEE Transactions on Power Systems, vol. 30, no. 6, pp. 3072-3081, 2015.

[16] M. Bahrman, J. Johansson and B. Nilsson, "Voltage source converter transmission technologies," in IEEE Power Engineering Society General Meeting, Toronto, 2003.

[17] O. Kukrer, S. Bayhan and H. Komurcugil, "Model-based Current Control Stratgey with Virtual Time Constant for Improved Dynamic Response of Three-Phase Grid-Connected VSI," IEEE Transations on Industrial Electronics, vol. 66, no. 6, pp. 4156-4165, 2019.

[18] A. Egea-Alvarez, A. Junyent-Ferré and O. Gomis-Bellmunt, "Active and reactive power control of grid connected distributed generation systems," in Modeling and Control of Sustainable Power Systems. Green Energy and Technology, Springer, Berlin, Heidelberg, 2012, pp. 47-81.

[19] H. Beltran, A. Egea-Àlvarez, S. Harrison and L. Xiu, "Technoeconomic assessment of energy storage technologies for inertia response and frequency support from wind farms," Energies, vol. 13, no. $13,2020$.

[20] E. Lidström and D. Wall, "Frequency support by synthetic inertia from variable speed wind turbines," in CIRED Workshop, Helsinki, 2016.

[21] S. C. Johnson, D. Papageorgiou, D. Mallapragada, T. Deetjen, J. D. Rhodes and M. E. Webber, "Evaluating rotational inertia as a component of grid reliability with high penetrations of variable renewable energy," Energy, vol. 180, pp. 258-271, 2019. 